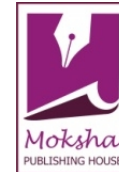

Research Article

www.ijrap.net

\title{
PREPARATION OF IMMEDIATE RELEASE TABLETS OF REPAGLINIDE BY A SOLUBILITY ENHANCER AND HOT-MELT EXTRUSION METHOD \\ Rramaswamy Ravikumar ${ }^{1}$, Mani Ganesh ${ }^{1}$, Ranganathan Hariprasad ${ }^{2}$, Hyun Tae Jang ${ }^{1}$ * \\ ${ }^{1}$ Department of Chemical Engineering, Hanseo University, 360 Daegok-ri, Seosan-si 31962, Chungcheongnam-do, South Korea \\ ${ }^{2}$ Department of Pharmaceutical Analysis, PSG College of Pharmacy, Coimbatore, Tamil Nadu, India
}

Received on: 23/08/16 Revised on: 26/09/16 Accepted on: 29/09/16

*Corresponding author

E-mail: htjang@hanseo.ac.kr

DOI: $10.7897 / 2277-4343.075201$

\begin{abstract}
To enhance the solubility of Repaglinide, we attempted to use Plasdone S 630, a novel solubility enhancer. Followed by the hot-melt extrusion method and made into a tablet dosage form. The prepared dosage forms subjected to all pre-compression and post-compression parameters evaluations. The data obtained from in-vitro drug release suggested that the trial-11 is the ideal formulation among all other formulations. The in-vitro release was also profiling around $95 \%$ within 45 minutes. The hardness of the prepared tablets was around $10-12 \mathrm{~kg} / \mathrm{cm}^{2}$ with the friability was less than $1 \%$. So, this method could apply on the regular basis for formulating the tablet dosage forms.
\end{abstract}

Keywords: Hot-melt extrusion, FT-IR, DSC, Repaglinide, Plasdone S 630, Solubility.

\section{INTRODUCTION}

The ideal route for administering a medicine is the oral route because of its convenience and ease to ingestion. While administering the solid dosage forms orally, as an initial step it will undergoes disintegration followed by dissolution and absorption in the GI tract ${ }^{1}$. But, the oral formulation with poor solubility is a greater limitation for the formulation scientists ${ }^{2}$. So, solubility enhancement should be the prime concern for a dosage form to get ideal bioavailability.

Repaglinide (RG), a meglitinide class of drug, is used for the treatment of non-insulin dependent diabetes mellitus (NIDDM). It induces an early insulin response to meals decreasing postprandial blood glucose levels. In comparison to metformin, sulfonylureas, and thiazolidinediones, the meglitinides are more efficient in lowering the postprandial blood. The metabolism of repaglinide will extensively be taken place in the liver and excretes in bile. The metabolites of repaglinide are not efficient enough to reduce the blood glucose level. It also reported being eliminated in feces around $90 \%$ and urine $8 \%{ }^{3}$.

With a low water solubility $\left(34 \mu \mathrm{g} / \mathrm{ml}\right.$ at $37{ }^{\circ} \mathrm{C}$ ) and high lipophilicity $(\log \mathrm{P}=3.97)$, Repaglinide belongs to Biopharmaceutics Classification System (BCS) class drug ${ }^{3}$. So, there are challenges on increasing the dissolution and bioavailability of the drug. As per the BCS, poor water soluble drugs are coming under the BCS classes of II and $\mathrm{IV}^{4}$. This poor solubility leads to poor bioavailability.

Though, studies state that the dissolution and oral absorption enhanced by using HP- $\beta-C D$, still, there are some difficulties in making the formulation with good solubility and absorption. So, a simple method that would not only improve the dissolution of Repaglinide but also be suitable for industrial production is much needed.
For enhancing the solubility of a drug candidate, several techniques are being used as; particle size reduction, solid dispersion, crystal modification, lipid-based system, $\mathrm{pH}$ changes, surfactants etc $^{5}$. For the hydrophobic drugs; carbohydrates, surfactants, super disintegrants and polymers like polyvinylpyrrolidone, polyethylene glycols, hydroxypropyl methylcellulose, mannitol, etc are used to enhance the solubility ${ }^{6,7}$. Also, techniques for increasing the surface area or surface's wetting properties, curbing the boundary layer thickness, improving the sink conditions for dissolutions. Further, various solubility enhancement strategies in solid dispersions can also be used, such as fusion (melting), solvent evaporation, lyophilization (freeze drying), melt agglomeration, extruding, spray drying, use of surfactant, electrostatic spinning method, and supercritical fluid technology.

In this way, hot-melt extrusion technique is emerging in the recent years as the number of poorly soluble new chemical entities is surging recently ${ }^{8,9}$. The main advantages of this method are its simplicity, economic and less time consumption. Hot-melt extrusion possibly makes these entities orally more bioavailable. Further, hot-melt extrusion is a robust manufacturing process which can adopt practically in the pharmaceutical industry ${ }^{10}$. Though the technology mandatorily required the materials to withstand the elevated temperatures and pressures, this hot-melt extrusion process is importantly useful to enhance the solubility of the poorly soluble drug entities to improve the bioavailability of the drug for the desired action with minimal toxicity.

In this present work, an attempt is made to improve the solubility of Repaglinide by hot-melt extrusion method along with the aid of a novel solubility enhancer Plasdone S 630 which possibly makes Repaglinide to soluble more which will lead to more bioavailability. Further, hot-melt extrusion is a robust manufacturing process, and the Plasdone S 630, a matrix polymer for solid dispersion can adopt practically in the 
pharmaceutical industry on the routine basis for preparing tablet dosage forms.

\section{MATERIALS AND METHODS}

Repaglinide was gifted by Pharmatrain, Hyderabad, India. Plasdone S 630, Kollidon VA 64, Span 20, Poly Ethylene Glycol (PEG) 4000, Aerosil, Magnesium Stearate, Croscarmellose Sodium, Crospovidone, MCC pH 112 and Lactose Monohydrate flow lac-100 were obtained from S.D. fine chemicals limited, Hyderabad (India). Analytical grade reagents were procured for all other works. Freshly prepared distilled water was used throughout the work. Repaglinide immediate release (IR) tablets were prepared by direct compression method.

\section{Saturation solubility}

Solubility of RG was measured in $0.1 \mathrm{~N} \mathrm{Hcl}, \mathrm{pH} 6.8$ and 7.4 phosphate buffer solutions. To a $50 \mathrm{~mL}$ conical flask, a large quantity of the drugs was added and shaken for $72 \mathrm{~h}$ in a rotary shaker. Then the saturated solution was subjected to filtration in a $0.45 \mu$ membrane filter, the absorbance of filtered solutions was determined, and an amount of drug solubilized was calculated.

\section{Polymer-drug interaction study}

\section{FT-IR Spectroscopic Analysis}

FT-IR spectroscopy (NICOLET-200, Thermo, USA) was used to find the drug-polymer interactions. $10 \mathrm{mg}$ of $\mathrm{RG}$ alone and mixture of the drug with polymer were weighed and mixed properly with potassium bromide uniformly. A thin semitransparent pellet was made by compressing a little amount of the sample in a pellet press. The IR-spectrum of the pellet was recorded at $450-4000 \mathrm{~cm}^{-1}$ by taking air as the reference and compared to study any interference.

\section{Differential Scanning Calorimetry (DSC)}

Differential scanning calorimetry (DSC) was performed using DSC (Scinco Co. Ltd, Seoul, Korea) calorimeter to study the thermal behaviours of drug alone and the mixture of drugs and polymer. The samples were heated in sealed aluminium pans under nitrogen flow $(80 \mathrm{ml} / \mathrm{min})$ at $10^{\circ} \mathrm{C} / \mathrm{m}$ heating rate from $25^{\circ} \mathrm{C}$ to $450^{\circ} \mathrm{C}$. The empty aluminium pan was used as the reference. The spontaneity of the heat transition was measured as a function of temperature for the drug and drug - polymer mixture.

Preparation of Repaglinide immediate release tablets by using hot-melt extrusion technique

The different drug to polymer ratios was used to prepare 15 batches of Repaglinide tablets by the hot-melt extrusion method. As a first step active pharmaceutical ingredient (API), Plasdone S 630 and Aerosil sieved through \#no. 30 ASTM and granulated in rapid mixer granulator with Span 20 or PEG 4000 for 3 minutes which was passed through hot-melt extruder at different zones with different temperatures (Table 1). Then the extruded materials were milled using conical mill at 15,000 rpm by excluding the magnesium stearate; all other extra granular blends were sieved through \#no. 30 ASTM and mixed for ten minutes. Magnesium stearate alone was passed through sieve \#no. 60 ASTM. This sieved magnesium stearate was mixed all together with the previous extra granular blended mix and compressed into tablets.

\section{Physicochemical evaluation of tablets}

\section{Micrometric properties of pre-compressed powder}

The flow properties of the pre-compressed powders of various batches were determined by the simple angle of repose using fixed-base cone method. A glass funnel was cinched with its tip positioned at a fixed height $(\mathrm{H})$ above graph paper placed on a horizontal surface. The sample was poured through the funnel until the apex of the conical pile touched to the tip of the pipe. The height and radius of the heap were measured. The experiment was repeated in triplicate, the angle of repose $(\tan \theta)$ was calculated using the following equation:

$$
\text { Angle of Repose }=\tan ^{-1}(\mathrm{~h} / \mathrm{r})
$$

Where, h- height of the cone, $r$ - circular base radius.

\section{Density measurements}

The bulk density apparatus was used to evaluate the bulk and tapped densities of the pre-compressed powder. Previously measured quantity of the formulated granules was transferred to a 50cc graduated measuring cylinder. The filled cylinder fitted with bulk density apparatus and its timer knob adjusted for 500 tapings. Then, the bulk volume before and after the 500 tapings was noted. Tapped density was performed in the same way as the bulk density measurement. The experiment repeated for triplicate values ${ }^{11}$. Following equations were used to measure the densities of the different batch granules.

$$
\begin{aligned}
& \text { Bulk density }\left(\mathrm{D}_{\mathrm{b}}\right)=\text { Sam. Wt. }(\mathrm{g}) / \text { Apparent sam. Vol. }\left(\mathrm{V}_{0}\right) \\
& \text { Tapped density }\left(\mathrm{D}_{\mathrm{t}}\right)=\text { Sam wt. }(\mathrm{g}) / \text { Volume after tapping }\left(\mathrm{V}^{\mathrm{f}}\right)
\end{aligned}
$$

Following equation was used to calculate the compressibility index or Carr's index value of pre-compressed powder;

$$
\text { Carr's or compressibility Index }(\%)=D_{t}-D_{b} / D_{t} \times 100
$$

Hausner's ratio of pre-compressed powder determined by comparing the tapped density to the bulk density by using the equation;

$$
\text { Hausner's Proportion }(\mathrm{H})=\mathrm{D}_{\mathrm{t}} / \mathrm{D}_{\mathrm{b}}
$$

\section{Weight variation, Hardness and Friability}

Around 20 tablets were weighed individually and calculated its average weight for weight variation parameter.

For each formulation, the hardness of 10 randomly selected tablets was examined using a Pfizer hardness tester (A-101 Secor, India) by measuring in $\mathrm{kg} / \mathrm{cm}^{2}$.

The Roche friabilator (USP EF-2, Electro Lab.) was used to evaluate the percent friability. From each batch, ten tablets were weighed and placed in the plastic chamber. The friabilator rotated for 4 minutes or 100 revolutions. After 100 revolutions tablets were removed from the chamber and re-weighed. The following formula was used to determine the percentage of weight loss or friability;

$$
\begin{gathered}
\text { Friability }(\%)=\text { Weight loss after friability } / \text { Weight before } \\
\text { friability } \times 100
\end{gathered}
$$

Content uniformity and Assay

Ten tablets were weighed and powdered from each batch. The $10 \mathrm{mg}$ powder equivalent of Repaglinide was suspended in 100 $\mathrm{ml}$ of water containing $10 \mathrm{ml}$ of methanol. The resulting solution 
was transferred into a conical flask, closed and it was shaken for $12 \mathrm{~h}$ by using a mechanical shaker at room temperature. Next day it was stirred for 15 minutes. Filtered the solution and diluted suitably. Then the diluted filtrate was measured for absorbance at $\lambda$-max $243 \mathrm{~nm}$ using UV- Visible spectrophotometer (SHIMADZU, Mini-2140 series, Japan). The drug content in the tablet was determined by using the formula;
In-vitro drug release studies Drug release estimation was performed with various batches of the compressed Repaglinide tablets by using citrate buffer with $\mathrm{pH} 5.0$ for 90 mins using dissolution test apparatus USP XIII paddle type (Model-TDT08L, Electrolab Mumbai, India), $75 \mathrm{rpm}$ in $900 \mathrm{ml}$ dissolution medium and temperature maintained at $37 \pm 0.5^{\circ} \mathrm{C}$. Samples $(5 \mathrm{ml})$ were collected at $5,10,15,30,45,60$ and 90 min period. After each sampling, the equal volume of the medium was replaced with the same volume of the fresh medium. The sample was filtered through a $0.45 \mu$ membrane filter and diluted with appropriate dilution with the respective medium. Then estimate the Repaglinide concentration in the solution by using UVVisible spectrophotometry measured at $\lambda$-max $243 \mathrm{~nm}$. The absorbance measured at different time intervals; then, the concentration, amount of drug released, and the percentage of drug release were calculated.

Mechanism of drug release kinetics studies The in-vitro dissolution data subjected to kinetic treatment to get the order of release and best-fit model for the formulations. The various kinetic equations like zero-order (\% release $\mathrm{v} / \mathrm{s}$ time $)$, firstorder (Log \% retained v/s time), Higuchi matrix (cumulative \% drug released vs. square root of time) and Korsemeyer and Peppa's equation (Log cumulative percent drug released versus $\log$ time). The coefficients of correlation (r) values were calculated for the linear curves obtained by regression analysis plots.

\section{Zero-order kinetics}

Following equation was used to determine the drug release followed by the zero-order kinetics;

$$
\text { Concentration }(\mathrm{C})=\text { Initial concentration }(\mathrm{C} i)-\mathrm{K}_{0} \mathrm{t}
$$

Where, $\mathrm{C}$ is the amount of drug dissolved in time $\mathrm{t}, \mathrm{C}_{\mathrm{i}}$ is the initial amount of drug in the solution (most times $\mathrm{C}=0$ ), and $\mathrm{K}_{0}$ is the zero order release constant. When the data plotted as (\%) cumulative drug release versus time; if the plot is linear, then the data obeys zero-order release kinetics with a slope equal to $\mathrm{K}_{0}$.

\section{First-order kinetics}

Following equation was used to determine the drug release followed the first-order kinetics;

$$
\text { Log concentration }(\mathrm{C})=\log \text { of } \mathrm{C}_{0}-\mathrm{K} t / 2.303
$$

Where; $\mathrm{C}=$ remaining drug concentration at time $(\mathrm{t})$.

$C_{0}=$ Initial drug concentration, $\mathrm{K}=$ First-order rate constant (h-1)

When the calculated data was plotted as log cumulative percent drug remaining versus time obtained a straight line that indicates that the release follows first order kinetics. The constant " $\mathrm{K}$ " can be obtained by multiplying 2.303 with slope values.

\begin{tabular}{|c|c|c|c|c|c|c|c|c|c|c|c|c|c|c|c|}
\hline Ingredients & T-1 & T-2 & T-3 & T-4 & T-5 & T-6 & T-7 & T-8 & T-9 & T-10 & T-11 & T-12 & T-13 & T-14 & T-15 \\
\hline \multicolumn{16}{|c|}{ Intragranular } \\
\hline Repaglinide & 5 & 5 & 5 & 5 & 5 & 5 & 5 & 5 & 5 & 5 & 5 & 5 & 5 & 5 & 5 \\
\hline Plasdone S 630 & 100 & 150 & 0 & 0 & 75 & 100 & 100 & 100 & 100 & 100 & 100 & 100 & 100 & 100 & 100 \\
\hline Kollidone VA 64 & 0 & 0 & 100 & 150 & 0 & 0 & 0 & 0 & 0 & 0 & 0 & 0 & 0 & 0 & 0 \\
\hline Span 20 & 5 & 5 & 5 & 5 & 5 & 0 & 0 & 0 & 10 & 7.5 & 7.5 & 7.5 & 7.5 & 7.5 & 7.5 \\
\hline PEG 4000 & 0 & 0 & 0 & 0 & 0 & 5 & 10 & 0 & 0 & 0 & 0 & 0 & 0 & 0 & 0 \\
\hline Aerosil & 05 & 05 & 05 & 05 & 05 & 05 & 05 & 05 & 05 & 05 & 05 & 05 & 00 & 05 & 05 \\
\hline Magnesium stearate & 0 & 0 & 0 & 0 & 0 & 0 & 0 & 0 & 0 & 0 & 0 & 0 & 5 & 0 & 0 \\
\hline $\begin{array}{l}\text { Crosscaramellose } \\
\text { Sodium }\end{array}$ & 10 & 10 & 10 & 10 & 10 & 10 & 10 & 10 & 10 & 10 & 10 & 10 & 10 & 0 & 15 \\
\hline Crospolyvidone & 0 & 0 & 0 & 0 & 0 & 0 & 0 & 0 & 0 & 0 & 0 & 0 & 0 & 10 & 0 \\
\hline \multicolumn{16}{|c|}{ Extra Granular } \\
\hline Croscarmellose Sodium & 5 & 5 & 5 & 5 & 5 & 5 & 5 & 5 & 5 & 5 & 5 & 5 & 5 & 0 & 5 \\
\hline Crospolyvidone & 0 & 0 & 0 & 0 & 0 & 0 & 0 & 0 & 0 & 0 & 0 & 0 & 0 & 5 & 0 \\
\hline Mccph112 & 117 & 67 & 117 & 67 & 142 & 117 & 112 & 122 & 112 & 114.5 & 30 & 30 & 30 & 30 & 30 \\
\hline $\begin{array}{l}\text { Lactose Monohydrate } \\
\text { flow lac } 100\end{array}$ & 0 & 0 & 0 & 0 & 0 & 0 & 0 & 0 & 0 & 0 & 84.5 & 84.5 & 84.5 & 84.5 & 79.5 \\
\hline Magnesium Sterate & 3 & 3 & 3 & 3 & 3 & 3 & 3 & 3 & 3 & 3 & 3 & 3 & 3 & 3 & 3 \\
\hline Total Weight & 250 & 250 & 250 & 250 & 250 & 250 & 250 & 250 & 250 & 250 & 250 & 250 & 250 & 250 & 250 \\
\hline
\end{tabular}

Table 1: Formulation table for Repaglinide IR tablets

Table 2: Solubility medium and the saturated quantity of Repaglinide

\begin{tabular}{|c|c|}
\hline Media & Saturation solubility $(\mathbf{m g} / \mathbf{m l})$ \\
\hline $0.1 \mathrm{~N} \mathrm{HCl}$ & 3.14 \\
\hline $\mathrm{pH} \mathrm{6.8} \mathrm{phosphate} \mathrm{buffer}$ & 0.292 \\
\hline $\mathrm{pH} \mathrm{7.4} \mathrm{phosphate} \mathrm{buffer}$ & 0.147 \\
\hline
\end{tabular}


Table 3: Micrometric evaluation parameters for the pre-compression blend of the Repaglinide formulations

\begin{tabular}{|c|c|c|c|c|c|}
\hline Formulations & Bulk Density & Tapped Density & Hausner's Ratio & Carr's Index & Angle Of Repose \\
\hline Trial-1 & 0.625 & 0.902 & 1.443 & 30.71 & 54.81 \\
\hline Trial-2 & 0.653 & 0.897 & 1.374 & 27.202 & 47.23 \\
\hline Trial-3 & 0.589 & 0.849 & 1.441 & 30.624 & 54.59 \\
\hline Trial-4 & 0.631 & 0.897 & 1.422 & 29.654 & 52.59 \\
\hline Trial-5 & 0.619 & 0.885 & 1.430 & 30.056 & 53.26 \\
\hline Trial-6 & 0.674 & 0.968 & 1.436 & 30.372 & 53.49 \\
\hline Trial-7 & 0.629 & 0.875 & 1.391 & 28.114 & 49.24 \\
\hline Trial-8 & 0.595 & 0.849 & 1.427 & 29.918 & 52.64 \\
\hline Trial-9 & 0.663 & 0.933 & 1.407 & 28.939 & 50.59 \\
\hline Trial-10 & 0.649 & 0.897 & 1.382 & 27.648 & 48.15 \\
\hline Trial-11 & 0.587 & 0.675 & 1.150 & 13.037 & 33.12 \\
\hline Trial-12 & 0.638 & 0.726 & 1.138 & 12.121 & 32.26 \\
\hline Trial-13 & - & - & - & - & - \\
\hline Trial-14 & 0.659 & 0.762 & 1.156 & 13.517 & 33.67 \\
\hline Trial-15 & 0.664 & 0.771 & 1.161 & 13.878 & 33.94 \\
\hline
\end{tabular}

Table 4: Micrometric evaluation parameters for the post-compression Repaglinide tablet formulation

\begin{tabular}{|c|c|c|c|c|c|}
\hline Formulations & $\begin{array}{c}\text { Weight } \\
\text { Variation }\end{array}$ & Hardness & $\begin{array}{c}\text { Disintegration Time } \\
\text { (Minutes) }\end{array}$ & Friability & Assay \\
\hline Trial-1 & Pass & $10-12$ & 13 & 0.253 & 98.93 \\
\hline Trial-2 & Pass & $7-8$ & 12 & 0.312 & 99.27 \\
\hline Trial-3 & Pass & $7-8$ & 12 & 0.168 & 100.52 \\
\hline Trial-4 & Pass & $10-12$ & 10 & 0.265 & 100.64 \\
\hline Trial-5 & Pass & $10-12$ & 14 & 0.243 & 99.64 \\
\hline Trial-6 & Pass & $10-12$ & 12 & 0.152 & 100.15 \\
\hline Trial-7 & Pass & $10-12$ & 11 & 0.142 & 98.68 \\
\hline Trial-8 & Pass & $10-12$ & 10 & 0.134 & 101.12 \\
\hline Trial-9 & Pass & $10-12$ & 13 & 0.261 & 100.53 \\
\hline Trial-10 & Pass & $10-12$ & 12 & 0.214 & 99.87 \\
\hline Trial-11 & Pass & $10-12$ & 11 & 0.143 & 100.46 \\
\hline Trial-12 & Pass & $10-12$ & 16 & - & - \\
\hline Trial-13 & - & - & - & 11 & 0.312 \\
\hline Trial-14 & Pass & $10-12$ & 11 & 99.54 \\
\hline Trial-15 & Pass & $10-12$ & & 0.152 & 99.91 \\
\hline
\end{tabular}

Table 5: $\mathbf{R}^{2}$ Values for zero order and first order kinetics

\begin{tabular}{|c|c|c|}
\hline \multirow{2}{*}{ Formulations } & \multicolumn{2}{|c|}{$\mathbf{R}^{2}$ Values } \\
\cline { 2 - 3 } & Zero order & First order \\
\hline Trial-1 & 0.878 & -0.988 \\
\hline Trial-2 & 0.862 & -0.957 \\
\hline Trial-3 & 0.889 & -0.957 \\
\hline Trial-4 & 0.878 & -0.977 \\
\hline Trial-5 & 0.890 & -0.988 \\
\hline Trial-6 & 0.921 & -0.992 \\
\hline Trial-7 & 0.911 & -0.997 \\
\hline Trial-8 & 0.954 & -0.997 \\
\hline Trial-9 & 0.866 & -0.983 \\
\hline Trial-10 & 0.832 & -0.925 \\
\hline Trial-11 & 0.856 & -0.959 \\
\hline Trial-12 & 0.945 & -0.974 \\
\hline Trial-13 & -- & -- \\
\hline Trial-14 & 0.927 & -0.995 \\
\hline Trial-15 & 0.866 & -0.955 \\
\hline
\end{tabular}




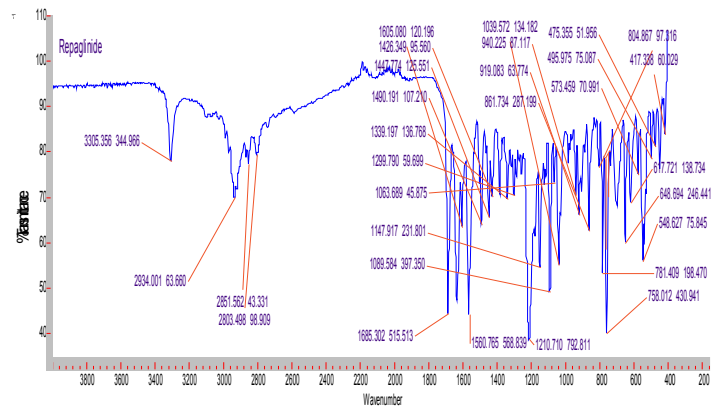

Figure 1: FT-IR spectrum of pure Repaglinide

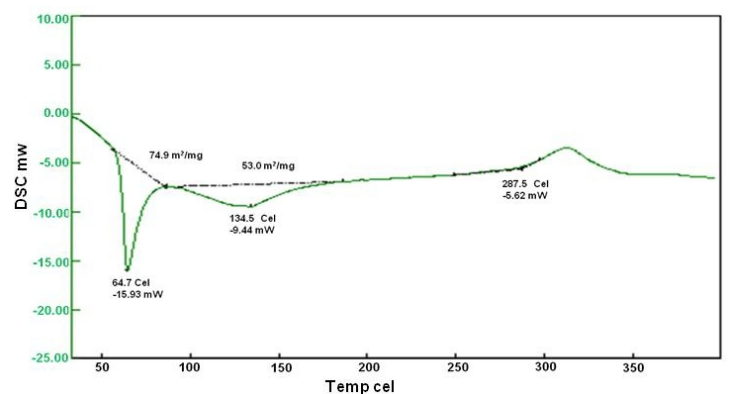

Figure 3: DSC Spectrum of the Repaglinide pure

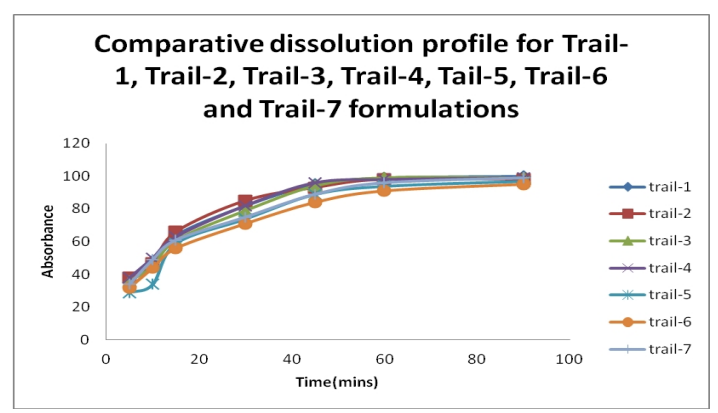

Figure 5: In-vitro drug release profiles of trial-1 to trial-7 formulation

\section{RESULTS AND DISCUSSION}

Characterization of Repaglinide

Solubility Saturation RG was experimentally found to be highly soluble in $0.1 \mathrm{~N}$ HCL followed by higher $\mathrm{pH}$ phosphate buffer. The solubility parameters and the amount solubilized shown in (Table 2).

FT-IR spectroscopy The FT-IR was used to observe the characteristic peaks of pure $\mathrm{RG}$ were obtained at $3305.3 \mathrm{~cm}^{-1}$, $1685.3 \mathrm{~cm}^{-1}$ and $1039.5 \mathrm{~cm}^{-1}$ corresponding to $\mathrm{N}-\mathrm{H}, \mathrm{C}=\mathrm{O}$ and C$\mathrm{N}$ were shown in (Figure 1). The spectrum (Figure 2) obtained for the ideal formulation of RG was compared with the spectral data of the pure RG and was found that the major peaks of drugs with polymer formulations were obtained as nearer values, and there were no considerable changes in IR peaks in all physical mixtures of drug and polymers. This data are suggesting that the drug was molecularly dispersed well with the absence of drug and polymer interactions.

Differential Scanning Calorimetry (DSC) DSC studies of the $\mathrm{RG}$ pure drug and the Repaglinide ideal formulations were

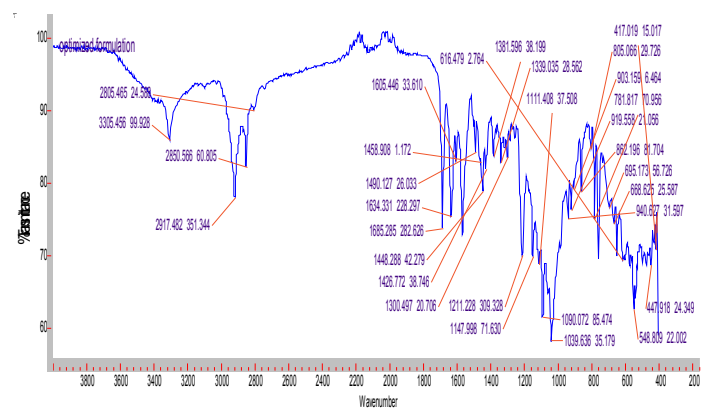

Figure 2: FT-IR spectrum of ideal Repaglinide formulation

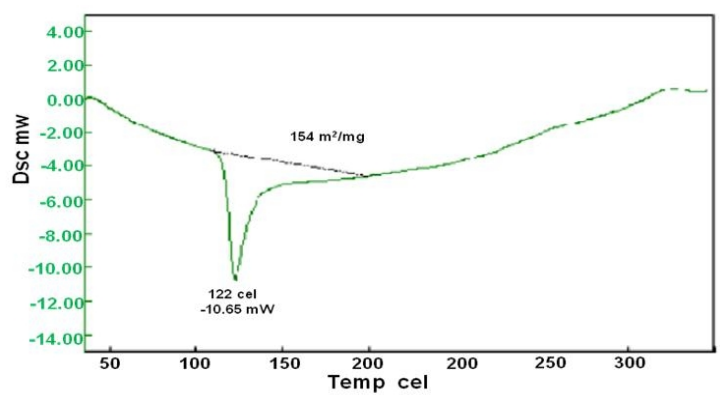

Figure 4: DSC Spectrum of the Repaglinide ideal formulation tablet

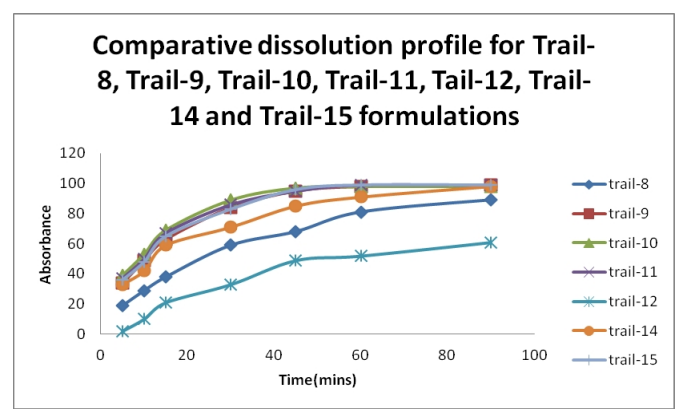

Figure 6: In-vitro drug release profiles of Trial-8 to Trial-15 formulations

shown in the (Figure 3) \& (Figure 4). Since the Repaglinide is crystalline in nature, the DSC thermogram is showing the peak at around $134^{\circ} \mathrm{C}$. The ideal tablet formulation shows the peak shift from $134.5^{\circ} \mathrm{C}$ to $122.5^{\circ} \mathrm{C}$ in the thermogram is evident that the slight amorphisation of the Repaglinide due to the dispersion with solubility enhancer Plasdone S 630 was occurred.

Micrometric properties of pre-compressed powder blends The flow property of the RG granule blend was evaluated, and the results were shown in the (Table 3 ). The bulk density and the tapped density for all formulations were found to be almost similar. The Hausner's ratio and Carr's index were determined to be in the range $\leq 18$ and 1.15 to 1.16 respectively, indicating good flow and compressibility of the blends. The angle of repose for all the formulations was found to be in the range of $32.26^{\circ}-33.94^{\circ}$

Micrometric properties of post-compressed formulation The post-compressed tablet formulation of Repaglinide was also evaluated for its micrometric properties and shown in the (Table 4). The weight variation of the tablets observed within pharmacopeial limit $\pm 7.5 \% \mathrm{w} / \mathrm{w}$ of standard deviation from the 
average. For the different formulations, the hardness was found to be between 10 and $12 \mathrm{~kg} / \mathrm{cm}^{2}$, indicating the satisfactory mechanical strength. The friability was $<1.0 \% \mathrm{w} / \mathrm{w}$ for all the formulations, which is an indication of the good mechanical resistance of the tablet. The drug content was within the limits of 98.0 to $102.0 \%$.

Evaluation of drug release kinetics All the batches from Trial1 to trial 15 of Repaglinide tablet formulations were subjected to various release kinetics like zero order kinetics and first order kinetics models in order to determine the release pattern of the drug. The in-vitro dissolution patterns were shown in the Figure $5 \& 6$ of the tablet formulations. The correlation coefficient $\left(\mathrm{R}^{2}\right)$ is given in Table 5 .

The $\mathrm{R}^{2}$ values of first order kinetic models are higher than the zero order kinetic model values which ascertaining that the drug is following the first order kinetics in the in-vitro release.

\section{CONCLUSION}

Among the various formulation trials, the trial 11 with the concentration of drug and Plasdone S 630 (1:20) and $20 \mathrm{mg}$ of span 20 was ideal enough to formulate the immediate release of Repaglinide, using hot-melt extrusion method. The dissolution rate of the proposed concentrations was also high. The drug release of this immediate release formulation was less than 45 minutes. So, from the data reported, the proposed method of preparation can be ideal for preparing immediate release tablets of Repaglinide.

\section{ACKNOWLEDGEMENT}

The authors gratefully acknowledge the financial aid, received from National Research Foundation of Korea (NRF), of the Ministry of Science, ICT and Future Planning (Grant no. 2014004694).

\section{REFERENCES}

1. Brahmankar DM, Sunil Jaiswal B. Biopharmaceutics and Pharmakokinetics - A Treatise. $1^{\text {st }}$ ed. Vallabh Prakasan Publishers; 2005.

2. Mittal Ankit, Yadav Manish, Choudhary Dinesh, Shrivastava Birendra. Enhancement of solubility of Lurasidone $\mathrm{HCl}$ using solid dispersion technique. Int. J. Res. Ayurveda Pharm. 2014;5(5):632-637 http://dx. doi.org/10.7897/2277-4343.055129

3. Marbury et al. Pharmacokinetics of repaglinide in subjects with renal impairment. Clin. Pharmacol. Ther. 2000; 67(1):7-15

4. Mahesh Kumar K, Anil B. Biopharmaceutics Drug Disposition Classification System: An Extenction of Biopharmaceutics Classsification system. Inter. Res. J. Pharm. 2012; 3(3): 05-10.

5. Wairkar SM, Guard RS. Solid Dispersions: Solubility Enhancement Technique for Poorly Soluble Drugs. Inter. J. Res. Pharma. Biomed. Sci. 2013; 4(3): 847.

6. Saharan VA, Kukkar V, Kaia M, Gera M. Dissolution Enhancement of Drugs. Inter. J. Health. Res. 2009; 2(2): 108.

7. Chaudhary MD, Sonawane RO, Zawar L, Nayak S, Bari SB. Solubility and dissolution enhancement of poorly water soluble glimepiride by using solid dispersion technique. Inter. J. Pharm. and Pharm. Sci. 2012; 4(5): 534-539.

8. Rauwendaal CH. Polymer Extrusion. Hanser Publishers; 1986.

9. Kruder GA. Extrusion: Encyclopedia of Polymer Science and Engineering (1) $2^{\text {nd }}$ ed. John Wiley \& Sons Inc., New York 1985; 571-631.

10. Crowley MM, Zhang F, Repka MA, Thumma S, Upadhye SB, Battu SK, McGinity JW, Martin C. Pharmaceutical Applications of Hot Melt Extrusion: Part I. Drug. Dev. Ind Pharm. 2007; 33(9):909-926.

11. Yunxia Bi, Sunada H, Yonezaywa Y, Danjo K, Otsuka A. Preparation and evaluation of compressed tablet rapidly disintegrating in the oral cavity. Chem. Pharm. Bull. 1996; 44(11): 2121-2127.

\section{Cite this article as:}

Rramaswamy Ravikumar, Mani Ganesh, Ranganathan Hariprasad, Hyun Tae Jang. Preparation of immediate release tablets of repaglinide by a solubility enhancer and hot-melt extrusion method. Int. J. Res. Ayurveda Pharm. Sep - Oct 2016;7(5):85-90 http://dx.doi.org/10.7897/2277-4343.075201 for the site content and articles published. The views expressed in articles by our contributing authors are not necessarily those of IJRAP editor or editorial board members. 